\title{
molecules
}

ISSN 1420-3049

www.mdpi.com/journal/molecules

Article

\section{Laccase Immobilized on a PAN/Adsorbents Composite Nanofibrous Membrane for Catechol Treatment by a Biocatalysis/Adsorption Process}

\author{
Qingqing Wang, Jing Cui, Guohui Li, Jinning Zhang, Dawei Li, Fenglin Huang and Qufu Wei * \\ Key Laboratory of Eco-Textiles, Ministry of Education, Jiangnan University, Wuxi 214122, China; \\ E-Mails:wqq888217@126.com (Q.W.); wykaojn@126.com (J.C.); leeanna101121@yeah.net (G.L.); \\ qq164542493@126.com (J.Z.); ldw19900323@163.com (D.L.); windhuang325@163.com (F.H.) \\ * Author to whom correspondence should be addressed; E-Mail: qfwei@jiangnan.edu.cn; \\ Tel.: +86-510-8591-3653; Fax: +86-510-8591-2009.
}

Received: 20 January 2014; in revised form: 6 March 2014 / Accepted: 6 March 2014 /

Published: 19 March 2014

\begin{abstract}
The treatment of catechol via biocatalysis and adsorption with a commercial laccase immobilized on polyacrylonitrile/montmorillonite/graphene oxide (PAN/MMT/GO) composite nanofibers was evaluated with a homemade nanofibrous membrane reactor. The properties in this process of the immobilized laccase on PAN, PAN/MMT as well as PAN/MMT/GO with different weight ratios of MMT and GO were investigated. These membranes were successfully applied for removal of catechol from an aqueous solution. Scanning electron microscope images revealed different morphologies of the enzyme aggregates on different supports. After incorporation of MMT or MMT/GO, the optimum $\mathrm{pH}$ showed an alkaline shift to 4 , compared to 3.5 for laccase immobilized on pure PAN nanofibers. The optimum temperature was at $55{ }^{\circ} \mathrm{C}$ for all the immobilized enzymes. Besides, the addition of GO improved the operational stability and storage stability. A $39 \% \pm 2.23 \%$ chemical oxygen demand (COD) removal from the catechol aqueous solution was achieved. Experimental results suggested that laccase, PAN, adsorbent nanoparticles (MMT/GO) can be combined together for catechol treatment in industrial applications.
\end{abstract}

Keywords: laccase; enzyme immobilization; adsorbent; catechol; adsorption 


\section{Introduction}

Laccase, a multicopper oxidase, has been widely used in various applications including paper manufacturing [1], wood processing [2], environmental bioremediation [3,4], food industry [5], as well as textile engineering [6]. With the increasing demand, laccase products have been customized for specific industrial applications. Though the high quality laccase production process has been improved over the last decades, industrial application of laccase is still hampered by a lack of long-term operational stability and the difficulty in recycling laccase.

Enzyme immobilization techniques are well recognized as a common way to overcome the drawbacks mentioned above. They provides a more convenient handling of the enzyme, facilitate its facile separation from the products, minimize or eliminate protein contamination of the product, exhibit low or no allergenicity, and facilitate efficient recovery, and reuse of the enzyme, thus enabling its cost-effective use in continuous operation. Aside from this, they provide generally enhanced stability under both storage and operational conditions [7]. Many different kinds of immobilization methods have been reported for laccase immobilization, for instance, entrapment, encapsulation, adsorption, covalent binding, self-immobilization, and different combinations of the aforementioned methods [8]. Among all those methods, adsorption is a relatively simple and inexpensive way to immobilize laccase and may therefore have a higher commercial potential than other methodologies [9]. The adsorption of laccase onto a support is based on ionic and/or other weak forces of attraction. The $\mathrm{pH}$ and ionic strength of the medium and the hydrophobicity of the support surface must be taken into account during the immobilization process [10]. Some studies have shown that adsorption is preferable to other techniques for the immobilization of the laccase from $T$. versicolor $[8,11]$.

As is known, there is no universal support surface for immobilization of all kinds of enzymes. The support should be insoluble and compatible with laccase, without unfavorable interactions between the enzyme and the support. Besides, the diffusion limitations should be minimized to facilitate the biocatalytic reaction [12]. Electrospun nanofibers have been considered as an ideal support due to their high surface area to volume ratio, high porosity and the interconnectivity of the electrospun nanofibers, which endows them with a low hindrance for mass transfer [13]. Polyacrylonitrile (PAN) nanofibers have been widely studied for enzyme immobilization due to their good mechanical properties, solvent resistance, abrasion resistance, and high tensile strength [14-18]. A very recent work reported by $\mathrm{Xu}$ et al. [16] used direct conjugation of laccase molecules onto the surface of chemically modified PAN electrospun nanofibers and the performance of the immobilized laccase in removing 2,4,6-trichlorophenol was investigated. The results showed that the operational properties and the storage stability of the immobilized enzymes were greatly improved. Gupta and Dhakate [18] immobilized lipase on electrospun PAN nanofiber membrane by both physical adsorption and covalent bonding. The lipase immobilized by physical adsorption showed higher transesterification and hydrolytic activities than that covalently linked or native lipase. All this makes the use of PAN nanofibrous membrane as a support to immobilize enzymes by physical adsorption seem a very promising and feasible process.

In this study, we adopted an easy and feasible adsorption method for the direct immobilization of the commercial laccase onto the surface of PAN, PAN/MMT, PAN/MMT/GO composite electrospun nanofibrous membranes without using any chemical modification. Since the PAN used in this work 
was obtained from an industrial product, which was polymerized with a second monomer (methyacrylate) and a third monomer (itaconic acid). The use of itaconic acid was expected to contribute reactive groups to improve the multipoint attachment between enzyme and the support. Besides, the MMT and GO nanolayers could adsorb the laccase reaction products and their properties in the oxidation and removal of catechol from aqueous solutions were investigated.

\section{Results and Discussion}

\subsection{Morphologies of MMT, GO, MMT/GO Composites, and PAN/MMT/GO Composite Nanofibers}

The topographies of MMT and GO are shown in Figure 1a,b. The pure MMT aggregates showed a spherical shape and had an average particle size of $85.6 \mathrm{~nm}$, while the GO showed a layered sheet structure with a fractal shape extended to more than $3 \mu \mathrm{m}$. Compared with MMT, the dimensions of GO were much larger than those of MMT aggregates, so after blending, MMT was wrapped in GO sheets, as presented in Figure 1c. For PAN/MMT/GO composite nanofibers, some nanoparticles can be clearly observed within the polymer matrix, as seen in Figure $1 \mathrm{~d}$.

Figure 1. (a) tapping mode topography of MMT. (b) tapping mode topography of GO. (c) TEM of MMT/GO complexes. (d) TEM of PAN/MMT/GO-2 composite nanofibers.
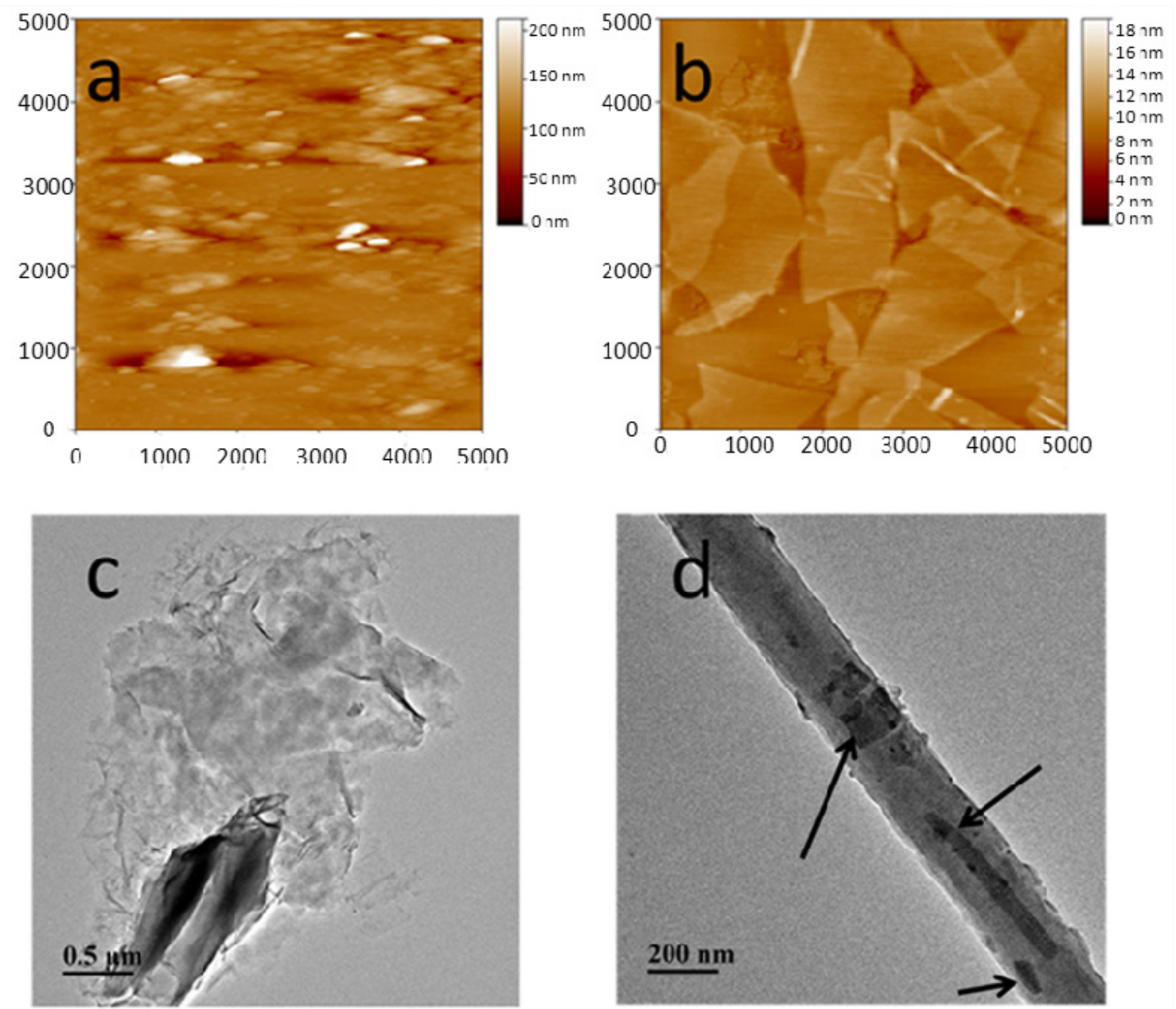


\subsection{Relationship between Enzyme Structure and Activity}

The SEM images of the nanofibrous membrane before and after enzyme immobilization are displayed in Figure 2. Before enzyme immobilization (see Figure 2a-e), the surface of the nanofibers was uniform. Compared with the pure PAN (see Figure 2a), the diameter of the composite nanofibers increased after the incorporation of the nanoparticles (see Figure $2 b$ ). With the addition of GO, beaded structures can be found in the fibrous structure.

Figure 2. SEM images of PAN, PAN/MMT, PAN/MMT-GO composite nanofibers before and after enzyme immobilization: (a and a') 0 wt. \% MMT; (b and b') 5 wt. \% MMT; (c and c') 5 wt. \% MMT/GO, MMT:GO = 9:1; (d and d') 5 wt. \% MMT/GO, MMT:GO = 8:2; (e and e') 5 wt. $\% \mathrm{MMT} / \mathrm{GO}, \mathrm{MMT}: \mathrm{GO}=7: 3$.

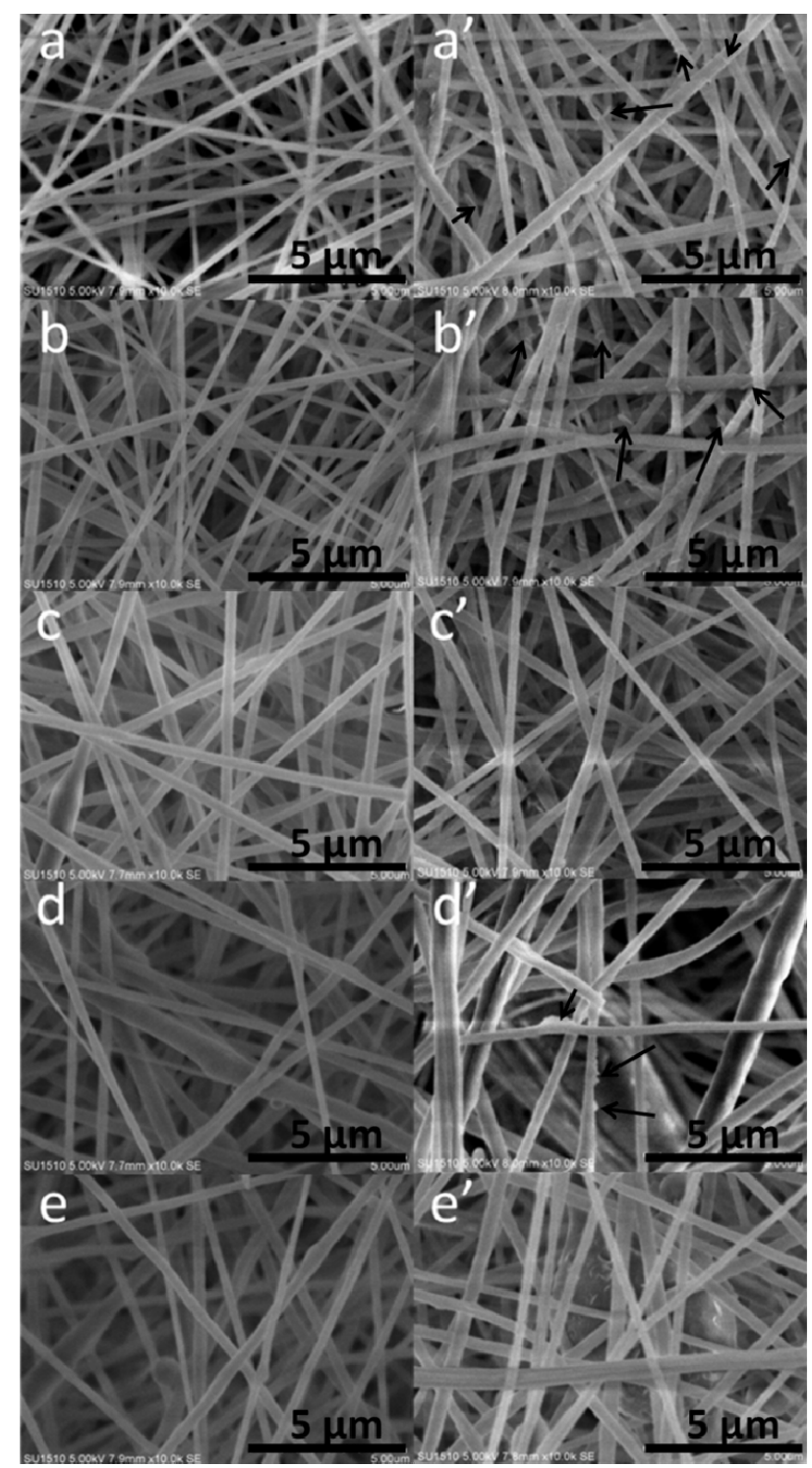

After enzyme immobilization (see Figure $2 \mathrm{a}^{\prime}-\mathrm{e}$ '), the nanofibers showed an increased fiber diameter due to the swelling behavior during the enzyme immobilization process. The immobilized enzyme aggregates formed different morphologies on the surface of the nanofibers, which can be divided into three types, i.e., strip-like structures, uniformly coated membrane [19,20], and also 
particle aggregates [21], illustrated schematically in Figure 3. This phenomenon might be caused by different enzyme-support linkages.

Figure 3. Three types of enzyme immobilization morphology (a) strip-shape. (b) uniform coating membrane. (c) particle aggregates.
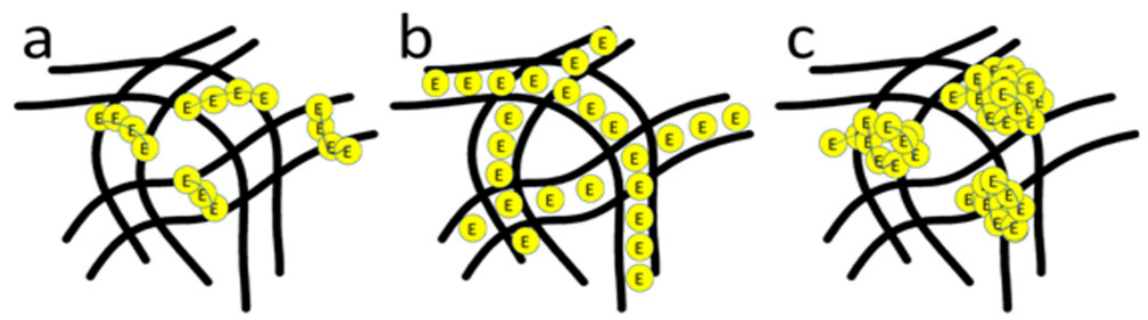

It was noticeable that the immobilized enzymes on PAN and PAN/MMT composite nanofibers formed an extraordinary strip-like structure and twined or half-twined around the nanofibers, which hadn't been reported before as far as we are aware. After addition of GO, the morphology of the immobilized laccase changed into a uniform coating structure. However, for PAN/MMT/GO-2, the case was a little bit different. Apart from the uniform coating, the immobilized laccase also presented an aggregated particle structure.

The activities of PAN-Lac, PAN/MMT-Lac, PAN/MMT/GO-1-Lac, PAN/MMT/GO-2-Lac, PAN/MMT/GO-3-Lac are presented in Figure 4a. Compared with PAN-Lac, the activities of the other four were relatively higher, which can be attributed to the nanoparticles incorporated inside the polymer matrix. Besides, the PAN/MMT/GO-1-Lac showed the highest activity, which can be partially explained by the improved enzyme loading of laccase, as revealed in the SEM analyses (Figure 2) combined with schematic illustrations (Figure 3). After enzyme immobilization, the enzyme diffusion rate and variations in the microenvironment was changed, leading to the loss of catalytic activity. $K_{m}$ values of the free and immobilized enzyme were revealed by Figure $4 \mathrm{~b}$.

Figure 4. The activities of immobilized laccase on PAN, PAN/MMT, PAN/MMT/GO composite nanofibers in an aqueous buffer solution ( $\mathrm{pH} 4.5$, temperature $30^{\circ} \mathrm{C}$ ).
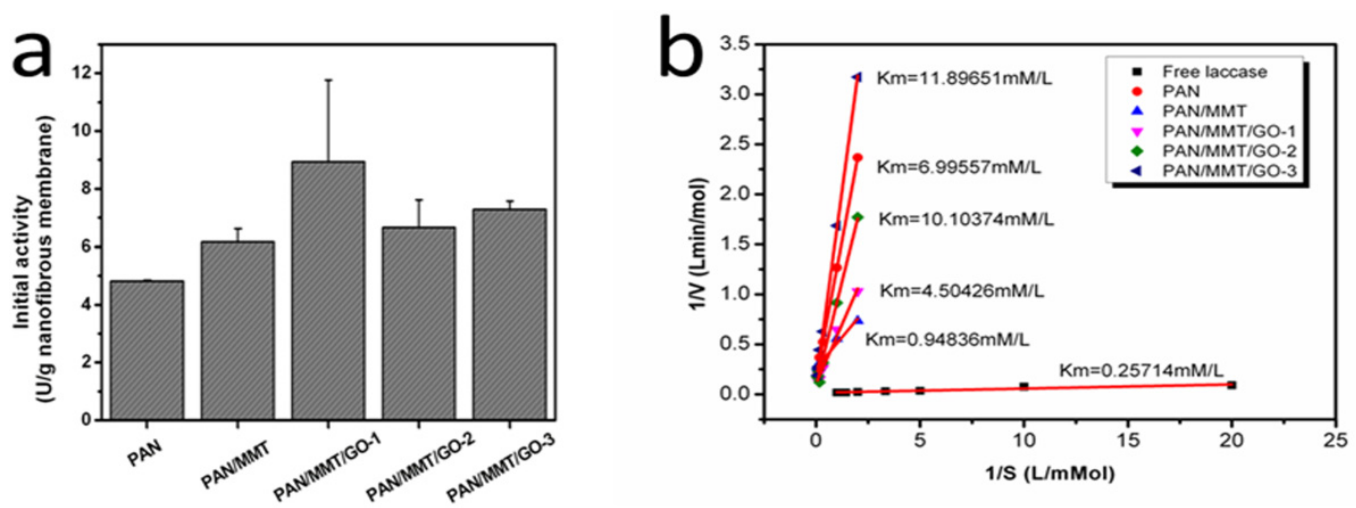

The $K_{m}$ values of the immobilized laccase were significantly higher than that of free laccase, which was due to the lower accessibility between substrate and active points of the immobilized enzyme caused by space barriers of the supports and the increased diffusion limitation [22]. Among those immobilized enzymes, PAN/MMT showed lowest $K_{m}$, which can be attributed to the adsorption 
properties of MMT [23]. With the addition of GO, the MMT was wrapped and the adsorption properties were weakened, leading to an increased $K_{m}$.

\subsection{Immobilized Enzyme Properties (pH, Temperature, Storage, Reusability)}

It can be seen that the activity of the immobilized enzyme is greatly dependent on $\mathrm{pH}$ (Figure 5). Changes in $\mathrm{pH}$ values could affect the enzyme conformation and the degree of dissociation the of the substrate, and thus the binding and catalysis effects between the enzyme molecules and substrate were also influenced. At a specific $\mathrm{pH}$ value the most appropriate combination between enzyme and the substrate can happen, resulting in a highly efficient catalysis. The laccase immobilized on PAN nanofibers showed a maximum activity at $\mathrm{pH} 3.5$, whereas the laccase immobilized on the composite nanofibers was most active at $\mathrm{pH}$. This could be explained by the cationic ion adsorption capability of the MMT. Some $\mathrm{H}^{+}$would gather around the nanofiber's surface, especially those areas there MMT exists, so the $\mathrm{pH}$ around the composite nanofiber was considered more acidic than that of the pure PAN at the same buffer solution, which finally leads to the right shift of the optimum $\mathrm{pH}$ value.

Figure 5. Optimum $\mathrm{pH}$ of the immobilized laccase on different supports.

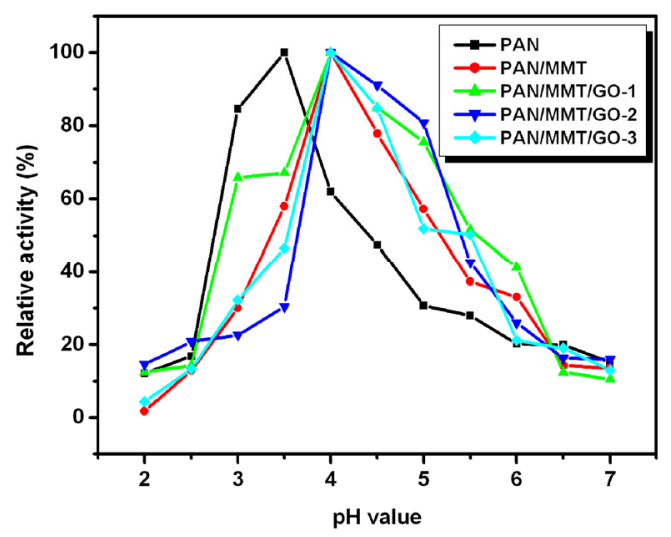

The influence of temperature on the activity of the immobilized laccase is shown in Figure 6 . The immobilized enzymes were incubated in buffer ( $\mathrm{pH} \mathrm{4.5)}$ for $5 \mathrm{~min}$ at different temperatures varying from 30 to $75^{\circ} \mathrm{C}$ before adding ABTS.

Figure 6. Optimum temperature of immobilized laccase on different suppports.

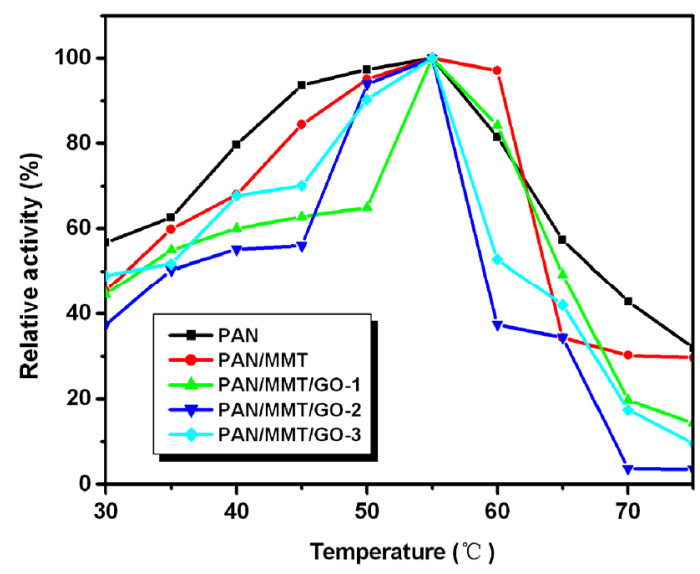


The immobilized enzymes showed a similar trend of temperature stability in the range of $30-75{ }^{\circ} \mathrm{C}$, while the laccase immobilized on PAN and PAN/MMT nanofibers showed relatively higher activity stability than the laccase immobilized on those nanofibers with GO, which may be at least in part due to the strip-like structure. All the immobilized enzymes showed relatively higher enzyme activity at the $45-60{ }^{\circ} \mathrm{C}$ range, with an optimum temperature at $55^{\circ} \mathrm{C}$.

The storage stability of the immobilized enzymes was also studied and the results are presented in Figure 7. The laccase immobilized on PAN/MMT/GO composite nanofibers showed relatively higher storage stability than that of PAN and PAN/MMT. The immobilized enzymes retained more than 50\% of their original activity after 20 days.

Figure 7. Storage stability of immobilized laccase on different supports.

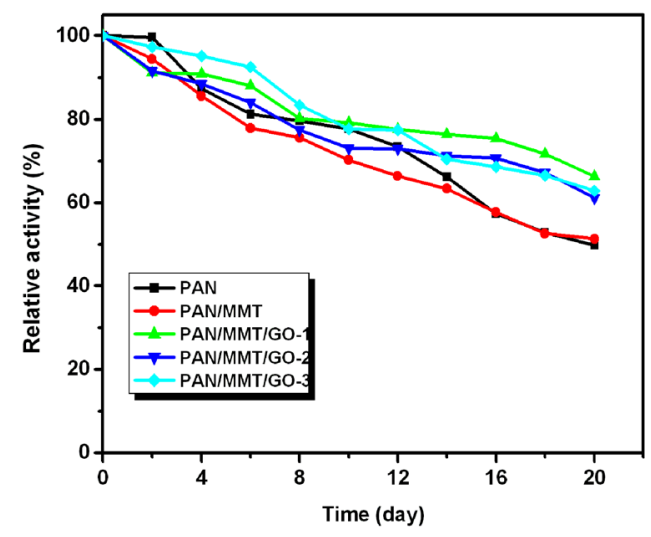

The operational stability of the immobilized laccase is presented in Figure 8. Reusability of immobilized enzyme is considered to be the most important in terms of industrial applications, because repeated use can reduce the production cost. The immobilized enzyme retained more than $50 \%$ of its initial activity after five repeated recycles.

Figure 8. Operational stability of the immobilized laccase on different supports.

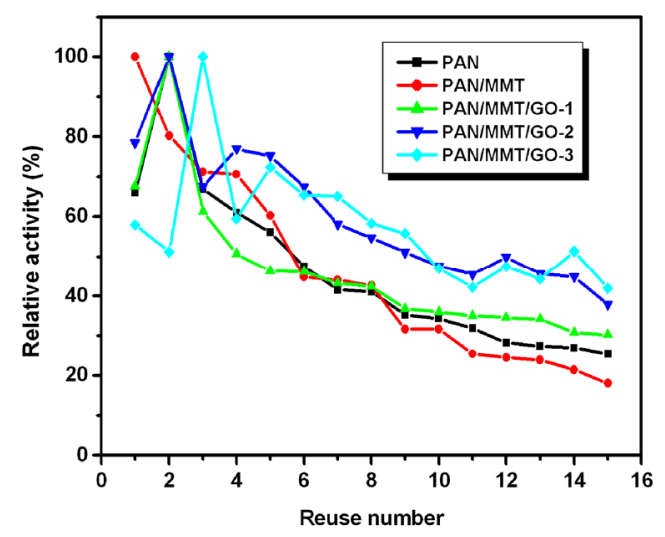

Decrease in the enzyme activity upon repeated usage was expected due to the fact that enzymes might denature during the operation process. However, for enzymes immobilized on PAN and PAN/MMT/GO nanofibrous membrane, the case was different. As is seen in Figure 8, the enzymes reached their highest activity at the second or third cycle. This phenomenon can be attributed to the flexible texture of the nanofibrous membrane. The membrane became loose and fluffy during repeated 
usage, contributing to more sites for the enzyme to reach the substrate. With the increase of GO concentration, the operational stability was improved. PAN/MMT/GO-3, after being used 15 times, retained $72 \%$ of the initial activity.

\subsection{Catechol Treatment by a Homemade Membrane Reactor Treatment}

An ultrafiltration device was used here as a membrane reactor, but instead of a micro-filtration membrane/ultra-filtration membrane (MF/UF), the electrospun nanofibrous membrane were used. As shown by the schematic illustration (Figure 9), laccase can catalyze the biotransformation of catechol into quinone, which then undergoes a series of non-enzymatic polymerization reactions leading to the formation of catechol-melanin complexes [24], which can be further adsorbed by MMT.

Figure 9. Schematic illustration of the homemade membrane reactor for catechol treatment.

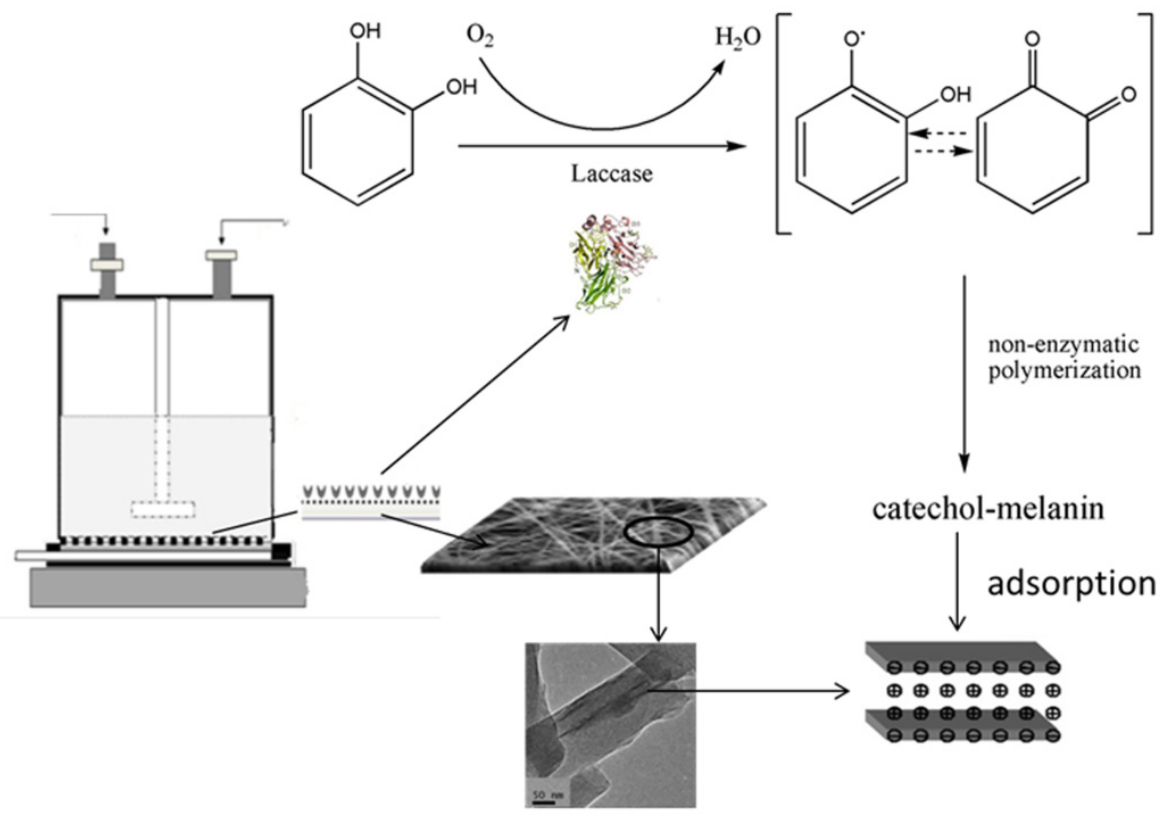

The UV-vis spectra showed that after laccase treatment, a peak at $410 \mathrm{~nm}$ which is due to the formation of quinone can be seen (Figure 10a). The end product solution first became darker and then changed to be clear again (Figure 10a inset), indicating the simultaneous occurrence of both quinone polymerization to form catechol-melanin and adsorption by MMT. The COD removal of the catechol solution by the laccase immobilized on the composite membranes is presented in Figure 10b. The PAN/MMT/GO-1 showed better COD removal capability than PAN/MMT. As is known, MMT can adsorb catechol [25], and those adsorbed catechol molecules can be protected from being transformed by laccase [26]. Since the overall adsorption capacity has been determined by the MMT itself, in this case, less catechol-melanin can be further adsorbed. After addition of GO, the process of catechol adsorption by wrapped MMT was slowed down, leading to a more complete catalytic reaction by laccase. The adsorption of catechol-melanin by MMT decreased the COD of the end solution. Further addition of GO showed a decreased COD removal ratio, which was due to the fact that less MMT was incorporated. 
Figure 10. (a) UV-vis spectra of end products from catechol catalyzed by laccase immobilized on PAN/MMT, the inset shows digital photographs of the solutions collected at different time intervals; (b) Catechol COD removal by the immobilized enzyme.
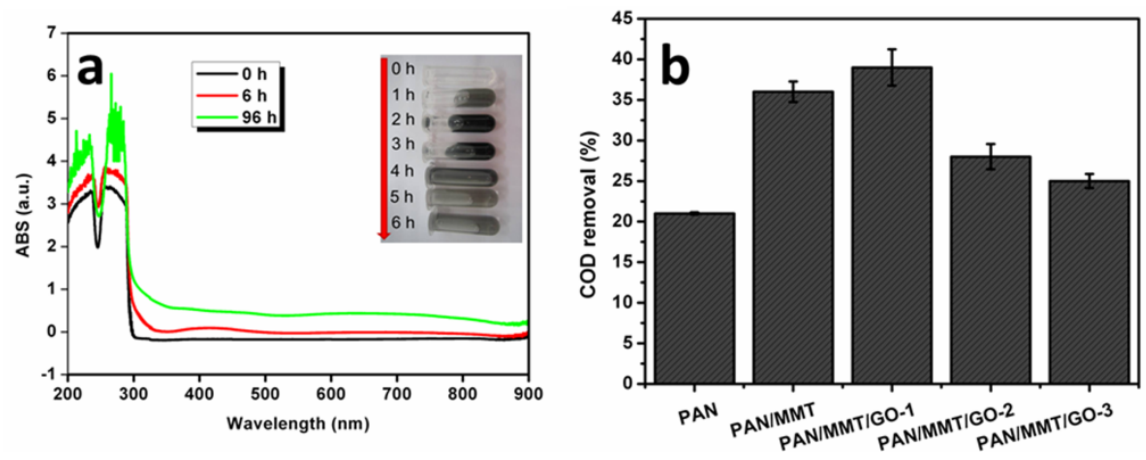

\section{Experimental}

\subsection{Chemicals}

Commercial laccase (3 U/mg) powder from Trametes versicolor was purchased from Wuhan Nuohui Pharmaceutical and Chemical Co., Ltd. (Wuhan, China). 2,2'-Azino-bis-(3-ethylbenzothiazoline-6-sulfonic acid, ABTS) was obtained from Richu Biosciences Co., Ltd. (Shanghai, China). GO was purchased from XF Nano, Inc. (Nanjing, China). MMT organically modified with hexadecyltrimethyl ammonium bromide (CTAB) was supplied by Zhejiang Fenghong Clay Chemicals Co., Ltd (Zhejiang, China). PAN ( $\mathrm{Mw}=50,000 \mathrm{~g} \mathrm{~mol}^{-1}$ ) was obtained from Shangyu Wu \& Yue Economic and Trade Co. Ltd (Zhejiang, China). All other reagents were of analytical grade and were purchased from Sinopharm Chemical Reagent Co., Ltd (Shanghai, China).

\subsection{Preparation of Electrospun PAN, PAN/MMT and PAN/MMT/GO Composite Nanofibers}

First, MMT and GO with an total weight of $150 \mathrm{mg}$ were dispersed in DMF by repeated stirring and sonication for about $3 \mathrm{~h}$. Then PAN powder $(3 \mathrm{~g})$ was added into the solution and magnetically stirred for about $24 \mathrm{~h}$ until a homogeneous solution was obtained. Then the solutions were electrospun at a positive voltage of $15 \mathrm{kV}$ with a working distance of $15 \mathrm{~cm}$, and a flow rate of $0.5 \mathrm{~mL} / \mathrm{h}$. The as-prepared electrospun composite nanofibers from solutions with different MMT/GO weight ratios were denoted as PAN/MMT-GO-1 (MMT:GO = 9:1), PAN/MMT-GO-2 (MMT:GO = 8:2), PAN/MMT-GO-3 (MMT:GO = 7:3).

\subsection{Immobilization of Laccase}

The laccase was dissolved in acetic acid/sodium acetate buffer $(\mathrm{pH}=4.5)$ solution at a concentration of $3 \mathrm{~g} / \mathrm{L}$ by magnetic stirring for $20 \mathrm{~min}$ in ice bath. The supernatant was collected by centrifuging for $5 \mathrm{~min}$ and used for the following immobilization process. The nanofibrous membrane (100 mg, accurately weighed) was placed into centrifuge tubes and then enzyme solution ( $8 \mathrm{~mL}$ per tube) was distributed into them. The immobilization process was conducted in the refrigerator at $4{ }^{\circ} \mathrm{C}$ 
for $12 \mathrm{~h}$. After that, the membranes were taken out and washed thoroughly with buffer solution until no enzyme can be detected in the washing solution.

\subsection{Determination of Immobilized Laccase Activity}

The immobilized enzyme activity was assayed at $30{ }^{\circ} \mathrm{C}$ using ABTS as the substrate. The detailed process was reported in our previous paper [27]. Three replications of all assays were conducted.

Kinetic tests were carried out at $30{ }^{\circ} \mathrm{C}$ in $100 \mathrm{mM}$ sodium acetate $(\mathrm{pH}=4.5)$ buffer using ABTS as the substrate, with the substrate concentration varied from 0.1 to $1 \mathrm{mM}$. The kinetic parameters of $K_{m}$ and $V_{\max }$ were calculated according to the Lineweaver-Burk double reciprocal models [28].

To determine the optimum $\mathrm{pH}$, the immobilized enzymes were incubated in buffers with $\mathrm{pH}$ ranging from 2 to 7 at $4{ }^{\circ} \mathrm{C}$ for $12 \mathrm{~h}$ and then assayed for activity, while the optimum temperature was determined by the activities of the immobilized enzymes incubated in buffers $(\mathrm{pH} \mathrm{4.5)}$ for 5 min at different temperatures varying from 30 to $75^{\circ} \mathrm{C}$ before adding ABTS.

The storage stability of the immobilized enzyme was determined by the activity retention ratio during storage at $4{ }^{\circ} \mathrm{C}$ in $100 \mathrm{mM}$ sodium acetate buffer solution ( $\mathrm{pH} 4.5$ ), at a regular intervals up to 20 days.

The operational stability was studied by repeated usage for 15 times, and the relative enzyme activity was recorded. The experiments were carried out at $30^{\circ} \mathrm{C}, \mathrm{pH} 4.5$. All the control samples were made with the buffer solution with the same $\mathrm{pH}$ value as the assayed one.

\subsection{Catecholl Degradation}

The catechol degradation process was carried out by our homemade membrane reactor. Instead of the MF/UF membrane, nanofibrous membrane after enzyme immobilization was used. The catechol powders were dissolved in buffer solution $(\mathrm{pH} 4)$ at a final concentration of $5 \mathrm{mM}$. Then, catechol solution $(300 \mathrm{~mL})$ was added into the bottle and magnetically stirred to achieve a more uniform reaction.

\subsection{Characterizations}

An atomic force microscope (AFM, Benyuan CSPM 4000, Guangzhou, China) was used in this work to observe the surface morphology of the MMT/GO hybrids. The samples were prepared by applying one droplet of the MMT or GO solution to the surface of a freshly peeled mica slip, and drying in an oven under $40{ }^{\circ} \mathrm{C}$. All the AFM images were obtained in the tapping mode.

A Hitachi H-7500 transmission electron microscope (TEM, Tokyo, Japan) was used to examine the assembly behavior of the MMT/GO hybrids and also the morphology of the resulting polymer matrix. The MMT/GO hybrids with the weight ratio of 8:2 and PAN/MMT/GO-2 composite nanofibers were chosen for this study. The experiments were operated under the voltage of $80 \mathrm{kV}$.

The morphology of the electrospun nanofibers before and after enzyme immobilization was characterized by scanning electron microscope (SEM, Quanta 200, Holland FEI Company, Beijing, China). The samples were sputter coated with a thin layer of Au nanoparticles to reduce the charging effects. 


\section{Conclusions}

PAN, PAN/MMT, and PAN/MMT/GO composite nanofibers were prepared by an electrospinning process and their properties as supports were examined by immobilizing laccase onto the fibers' surface. The immobilized laccase showed distinct morphologies on different supports. The activity of the immobilized laccase could reach as high as $8.7 \mathrm{U} / \mathrm{g}$ nanofibrous membrane. The $\mathrm{K}_{\mathrm{m}}$ value for PAN/MMT was small. The operation stability and storage stability were improved after the addition of GO. This membrane was further used in a homemade reactor for catechol treatment. The COD removal reached $39 \% \pm 2.23 \%$. This treatment method is simple, low cost and produces no secondary pollution, making it a good candidate for future industrial applications.

\section{Acknowledgments}

This work was financially supported by the National High-tech R\&D Program of China (No.2012AA030313), Changjiang Scholars and Innovative Research Team in University (No.IRT1135), National Natural Science Foundation of China (No.51006046 and No.51163014) and the Priority Academic Program Development of Jiangsu Higher Education Institutions.

\section{Author Contributions}

All listed authors contributed to this work. Qingqing Wang was responsible for the preparation of the membrane, the enzyme immobilization, analyzing the data as well as writing this manuscript; Jing Cui, Jinning Zhang, Guohui Li did the optimum $\mathrm{pH}$, temperature, storage stability and operational stability. Dawei Li did the catechol treatment. Qufu Wei and Fenglin Huang designed and obtained financial support.

\section{Conflicts of Interest}

The authors declare no conflict of interest.

\section{References}

1. Flory, A.R.; Requesens, D.V.; Devaiah, S.P.; Teoh, K.T.; Mansfield, S.D.; Hood, E.E. Development of a green binder system for paper products. BMC Biotechnol. 2013, 13, 1-14.

2. Fackler, K.; Kuncinger, T.; Ters, T.; Srebotnik, E. Laccase-catalyzed functionalization with 4-hydroxy-3-methoxybenzylurea significantly improves internal bond of particle boards. Holzforschung 2008, 62, 223-229.

3. Ashrafi, S.D.; Rezaei, S.; Forootanfar, H.; Mahvi, A.H.; Faramarzi, M.A. The enzymatic decolorization and detoxification of synthetic dyes by the laccase from a soil-isolated ascomycete, Paraconiothyrium variabile. Int. Biodeter. Biodegr. 2013, 85, 173-181.

4. Zhang, Y.; Zeng, Z.T.; Zeng, G.M.; Liu, X.M.; Liu, Z.F.; Chen, M.; Liu, L.; Li, J.; Xie, G. Effect of Triton X-100 on the removal of aqueous phenol by laccase analyzed with a combined approach of experiments and molecular docking. Colloid Surf. B 2012, 97, 7-12. 
5. Dhillon, G.S.; Kaur, S.; Brar, S.K.; Verma, M. Flocculation and Haze Removal from Crude Beer Using In-House Produced Laccase from Trametes versicolor Cultured on Brewer's Spent Grain. J. Agric. Food Chem. 2012, 60, 7895-7904.

6. Basto, C.; Tzanov, T.; Cavaco-Paulo, A. Combined ultrasound-laccase assisted bleaching of cotton. Ultrason. Sonochem. 2007, 14, 350-354.

7. Fernandez-Fernandez, M.; Sanroman, M.A.; Moldes, D. Recent developments and applications of immobilized laccase. Biotechnol. Adv. 2013, 31, 1808-1825.

8. Sheldon, R.A.; van Pelt, S. Enzyme immobilisation in biocatalysis: Why, what and how. Chem. Soc. Rev. 2013, 42, 6223-6235.

9. Bayramoglu, G.; Arica, M.Y. Immobilization of laccase onto poly(glycidylmethacrylate) brush grafted poly(hydroxyethylmethacrylate) films: Enzymatic oxidation of phenolic compounds. Mat. Sci. Eng. C-Mater. 2009, 29, 1990-1997.

10. Xu, X.H.; Lu, P.; Zhou, Y.M.; Zhao, Z.Z.; Guo, M.Q. Laccase immobilized on methylene blue modified mesoporous silica mcm-41/pva. Mat. Sci. Eng. C-Mater. 2009, 29, 2160-2164.

11. Qiu, H.J.; Xu, C.X.; Huang, X.R.; Ding, Y.; Qu, Y.B.; Gao, P.J. Immobilization of laccase on nanoporous gold: Comparative studies on the immobilization strategies and the particle size effects. J. Phys. Chem. C 2009, 113, 2521-2525.

12. Garcia-Galan, C.; Berenguer-Murcia, A.; Fernandez-Lafuente, R.; Rodrigues, R.C. Potential of different enzyme immobilization strategies to improve enzyme performance. Adv. Synth. Catal. 2011, 353, 2885-2904.

13. Wang, Z.G.; Wan, L.S.; Liu, Z.M.; Huang, X.J.; Xu, Z.K. Enzyme immobilization on electrospun polymer nanofibers: An overview. J. Mol. Catal. B.-Enzym. 2009, 56, 189-195.

14. Ye, P.; Xu, Z.K.; Wu, J.; Innocent, C.; Seta, P. Nanofibrous membranes containing reactive groups: Electrospinning from poly(acrylonitrile-co-maleic acid) for lipase immobilization. Macromolecules 2006, 39, 1041-1045.

15. Li, S.F.; Chen, J.P.; Wu, W.T. Electrospun polyacrylonitrile nanofibrous membranes for lipase immobilization. J. Mol. Catal. B.-Enzym. 2007, 47, 117-124.

16. Xu, R.; Chi, C.L.; Li, F.T.; Zhang, B.R. Laccase-Polyacrylonitrile Nanofibrous membrane: Highly immobilized, Stable, Reusable, and efficacious for 2,4,6-trichlorophenol removal. Acs. Appl. Mater. Inter. 2013, 5, 12554-12560.

17. Feng, Q.; Wang, Q.Q.; Tang, B.; Wei, A.F.; Wang, X.Q.; Wei, Q.F.; Huang, F.L.; Cai, Y.B.; Hou, D.Y.; Bi, S.M. Immobilization of catalases on amidoxime polyacrylonitrile nanofibrous membranes. Polym. Int. 2013, 62, 251-256.

18. Gupta, A.; Dhakate, S.R.; Pahwa, M.; Sinha, S.; Chand, S.; Mathur, R.B. Geranyl acetate synthesis catalyzed by Thermomyces lanuginosus lipase immobilized on electrospun polyacrylonitrile nanofiber membrane. Process. Biochem. 2013, 48, 124-132.

19. Huang, X.J.; Chen, P.C.; Huang, F.; Ou, Y.; Chen, M.R.; Xu, Z.K. Immobilization of Candida rugosa lipase on electrospun cellulose nanofiber membrane. J. Mol. Catal. B.-Enzym. 2011, 70, 95-100.

20. Zhu, J.; Sun, G. Lipase immobilization on glutaraldehyde-activated nanofibrous membranes for improved enzyme stabilities and activities. React. Funct. Polym. 2012, 72, 839-845. 
21. Chattopadhyay, S; Sen, R. A comparative performance evaluation of jute and eggshell matrices to immobilize pancreatic lipase. Process Biochem. 2012, 47, 749-757.

22. Cetinus, S.A.; Sahin, E.; Saraydin, D. Preparation of $\mathrm{Cu}(\mathrm{II})$ adsorbed chitosan beads for catalase immobilization. Food Chem. 2009, 114, 962-969.

23. Wang, L.; Wang, A.Q. Adsorption properties of Congo Red from aqueous solution onto surfactant-modified montmorillonite. J. Hazard. Mater. 2008, 160, 173-180.

24. Ma, H.L.; Kermasha, S.; Gao, J.M.; Borges, R.M.; Yu, X.Z. Laccase-catalyzed oxidation of phenolic compounds in organic media. J. Mol. Catal. B.-Enzym. 2009, 57, 89-95.

25. Shakir, K.; Ghoneimy, H.F.; Elkafrawy, A.F.; Beheir, S.G.; Refaat, M. Removal of catechol from aqueous solutions by adsorption onto organophilic-bentonite. J. Hazard. Mater. 2008, 150, 765-773.

26. Alm, M.Y.; Martinez, C.E.; Archibald, D.D.; Zimmerman, A.R.; Bollag, J.M.; Dec, J. Transformation of catechol in the presence of a laccase and birnessite. Soil Biol. Biochem. 2006, $38,1015-1020$.

27. Wang, Q.Q.; Peng, L.; Du, Y.Z.; Xu, J.; Cai, Y.B.; Feng, Q.; Huang, F.L.; Wei, Q.F. Fabrication of hydrophilic nanoporous PMMA/O-MMT composite microfibrous membrane and its use in enzyme immobilization. J. Porous Mat. 2013, 20, 457-464.

28. Wang, Q.Q.; Peng, L.; Li, G.H.; Zhang, P.; Li, D.W.; Huang, F.L.; Wei, Q.F. Activity of Laccase

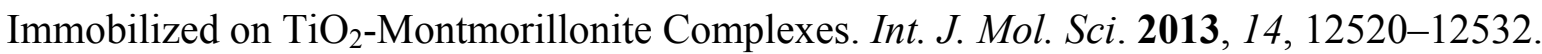

Sample Availability: Samples of the compounds including PAN, PAN/MMT, PAN/MMT-GO, PAN/MMT-GO-Lac composite nanofibrous membrane are available from the authors.

(C) 2014 by the authors; licensee MDPI, Basel, Switzerland. This article is an open access article distributed under the terms and conditions of the Creative Commons Attribution license (http://creativecommons.org/licenses/by/3.0/). 